Competing interests: None declared.

Ethical approval: The study was approved by the institutional review boards in the participating institutions and by Israel's ministries of health and the interior.

1 Innes KE, Byers TE. Preeclampsia and breast cancer risk. Epidemiology 1999;10:722-32.

2 Peleg L, Pesso R, Goldman B, Dotan K, Omer M, Friedman E, et al. Bloom syndrome and Fanconi's anemia: rate and ethnic origin of mutation carriers in Israel. Isr Med Assoc J 2002;4:95-7.

3 Davies AM, Prywes R, Tzur B, Wesikopf P, Sterk VV. The Jerusalem Perinatal Study. 1. Design and organization of a continuing, community-based, record linked survey. Isr J Med Sci 1969;5:1095-1106.

4 Israel Center for Disease Control. Investigation into the completeness of the Israel Cancer Registry. Methods and results. Publication 230. Israel Center for Disease Control, Oct 2003:31. (In Hebrew.)

5 Vatten LJ, Romundstad PR, Trichopoulos D, Skjaerven R. Pre-eclampsia in pregnancy and subsequent risk for breast cancer. $\mathrm{Br} J$ Cancer 2002;87:971-3.

6 Polednak AP, Janerich DT. Characteristics of first pregnancy in relation to early breast cancer. A case-control study. J Reprod Med 1983;28:314-8.

Thompson W, Jacobson H, Negrini B, Janerich D. Hypertension, pregnancy, and risk of breast cancer.J Natl Cancer Inst 1989;81:1571-4.

Troisi R, Weiss H, Hoover RN, Potischman N, Swanson CA, Brogan DR, et al. Pregnancy characteristics and maternal risk of breast cancer. Epidemiology 1998;9:641-7.
9 Roberts JM, Cooper DW. Pathogenesis and genetics of pre-eclampsia. Lancet 2001;357:53-6.

10 Struewing JP, Abeliovich D, Peretz T, Avishai N, Kaback MM, Collins FS, et al. The carrier frequency of the BRCA1 185delAG mutation is approximately 1 percent in Ashkenazi Jewish individuals. Nat Genet $1995 ; 11: 198-200$.

11 Pridjan G, Puschett JB. Preeclampsia. Part 2: experimental and genetic considerations. Obstet Gynecol Surv 2002;57:619-40.

12 Sherer DM, Abulafia O. Angiogenesis during implantation and placental and early embryonic development. Placenta 2001;22:1-13.

13 Odegard RA, Vatten LJ, Tore Nielsen S, Salvesen KA, Austgulen R. Risk factors and clinical manifestations of pre-eclampsia. Br J Obstet Gynaecol 2000;107:1410-6.

14 Zusterzeel P, Peters W, Visser W, Hermsen K, Roelofs H, Steegers E. A polymorphism in the gene for microsomal epoxide hydrolase is associated with preeclampsia. J Med Genet 2001;38:234-7.

15 Zhao H, Spitz MR, Gwyn KM, Wu X. Microsomal epoxide hydrolase polymorphisms and lung cancer risk in non-Hispanic whites. Mol Carcinog 2002;33:99-104.

16 Park JY, Schantz SP, Lazarus P. Epoxide hydrolase genotype and orolaryngeal cancer risk: interaction with GSTM1 genotype. Oral Oncol 2003;39:483-90.

17 Chikosi AB, Moodley J, Pegoraro RJ, Lanning PA, Rom L. 5,10 methylenetetrahydrofolate reductase polymorphism in black South African women with pre-eclampsia. Br J Obstet Gynaecol 1999;106:1219-20.

(Accepted 21 January 2004)

doi $10.1136 /$ bmj.38032.820451.7C

\title{
Incidence of breast cancer in Norway and Sweden during introduction of nationwide screening: prospective cohort study
}

\author{
Per-Henrik Zahl, Bjørn Heine Strand, Jan Mæhlen
}

\begin{abstract}
Objective To determine whether any increase in the incidence of breast cancer in women detected by mammography is compensated for by a drop in the incidence after age 69 , years when women are no longer invited for screening.

Design Population based cohort study of incidence of breast cancer during the introduction of nationwide screening programmes.

Setting Norway and Sweden.

Participants All women aged above 30 years (1.4 and 2.9 million, respectively, in 2000).

Main outcome measures Changes in age specific incidence rates of invasive breast cancer associated with the introduction of the screening programmes. Results As a result of screening the recorded incidence of breast cancer in women aged 50-69 years increased by $54 \%$ in Norway and $45 \%$ in Sweden. There was no corresponding decline in incidence after the age of 69 years.

Conclusions Without screening one third of all invasive breast cancers in the age group 50-69 years would not have been detected in the patients' lifetime. This level of overdiagnosis is larger than previously reported.
\end{abstract}

\section{Introduction}

Overdiagnosis in cancer screening is defined as the detection of low malignancy lesions that otherwise would not be detected in a patient's lifetime. It is often argued that overdiagnosis is not a problem for screening in breast cancer. ${ }^{1-3}$ For example, Boer et al predicted a 31\% increase in incidence of breast cancer in the Dutch mass screening programme that would be nearly fully compensated for by a strong drop in the incidence after age 69 years, when women are no longer invited for screening. ${ }^{1}$ Altogether there should be only $2 \%$ more breast cancers.

Olsen and Gøtzsche reported 30\% overdiagnosis in various screening trials. ${ }^{4}$ In Finland, incidence rates of breast cancer associated with screening have also increased. ${ }^{5}$ In Australia Harmer et al suggested that a recent increase in incidence is entirely due to mammographic screening. ${ }^{6}$

Organised nationwide screening for breast cancer with mammography in the age group 50-69 years started in Sweden in $1986{ }^{7}$ and in Norway in $1996 .{ }^{8}$ We studied the increase in age specific incidence rates for invasive breast cancer for the period 1971-2001 in Norway and Sweden.

Norwegian Institute of Public Health, PO Box 4404 Nydalen, N-0403 Oslo, Norway Per-Henrik Zahl senior statistician Bjørn Heine Strand statistician

Department of Pathology, Ullevål University Hospital, N-0407 Oslo, Norway Jan Mæhlen professor

Correspondence to: J Mæhlen jan.mahlen@ ioks.uio.no

BMJ 2004;328:921-4

\section{Methods}

In 1996-7 around 165000 women in four counties (Akershus, Oslo, Rogaland, Hordaland-the AORH counties) in Norway, covering $40 \%$ of the population, were invited to mammographic screening for the first time. They attended for second screening in 1998-9 and third in 2000-1. Screening in the 15 other counties started gradually later. In Sweden screening was introduced from 1986 to 1996 . More than $90 \%$ of the million women in the age group 50-69 years had been

This article was posted on bmj.com on 10 March 2004: http://bmj.com/ cgi/doi/10.1136/bmj.38044.666157.63 


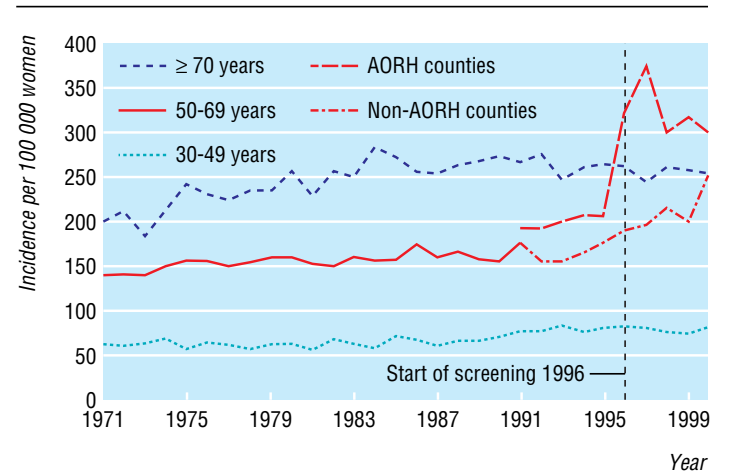

Fig 1 Age specific incidence of invasive breast cancer in Norway and for age groups 30-49, 50-69, and >69 years. From 1991 incidence rate for age group 50-69 years in Norway is split between AORH counties that started organised screening in 1996 and other counties

invited at least once by 1992. Later some women in the age group 70-74 years were also invited. In both countries the attendance rate among the invited women has been about $75 \%$. $^{79}$

We obtained specific rates of invasive breast cancer for the age groups 30-49, 50-69, and >69 years from nationwide cancer registers for the period 1971-2000. Our rates include only invasive disease; ductal carcinoma in situ has not been included.

We used Poisson regression models and relative risks to estimate the percentage change in age specific incidence rates of breast cancer after the introduction of nationwide screening programmes. We present relative risks with $95 \%$ confidence intervals and calculated estimates using the computer program EGRET.

The Norwegian dataset was analysed with an age-period model over the period 1991-2000. The period effects in 1991-5 were estimated with two linear trend parameters-one for the AORH counties and one for the non-AORH counties. As the non-AORH counties have always had a lower incidence than the AORH counties, ${ }^{8}$ we assumed this to be the case for 1991-2000.

We estimated the increase in incidence in the first screening round using an interaction parameter for age 50-69 years, the AORH counties, and the period 1996-7. The incidence increases in second and third screening rounds were estimated by using interaction with periods 1998-9 and 2000, respectively. We estimated the increase in incidence in the non-AORH counties in the period 1996-2000 analogously.

According to Boer et al the incidence is supposed to decline more in the age group 70-74 years than in age group $\geq 75 .^{1}$ We therefore estimated relative risks in the AORH counties in 2000 for the age group 70-74 years.

We estimated general period effects in Sweden before and after 1986 using two separate linear trend parameters to allow for an underlying increase in incidence during the period 1971-2000. The age specific increase was estimated with interaction variables between periods 1986-9, 1990-3, 1994-6, and 19972000 and age 50-69 years. Here we also tested for any decline in the age groups 70-74 years and 75-79 years using interaction terms between age and periods 1994-6 and 1997-2000, respectively.

In all analyses we adjusted for age using 5 year age intervals.

\section{Results}

Figure 1 shows age specific rates of invasive breast cancer in Norway. In the AORH counties there was no significant increase in rates during 1991-5 (table 1). In women aged 50-69 years who were invited to screening in 1996-7, however, the incidence increased by $82 \%$ (95\% confidence interval $70 \%$ to $96 \%$ ). In the second and third screening rounds the increases in incidence were $54 \%(42 \%$ to $66 \%)$ and $56 \%$ (42\% to $73 \%)$, respectively. There was no significant decline in women aged $70-74$ years in 2000 (about $80 \%$ of all women in the age group 70-74 years had been invited at least once to screening in 1996-9 before they turned 70 years).

Table 1 Estimated relative risks of breast cancer (excluding ductal carcinoma in situ) in Norway

\begin{tabular}{ll} 
& $\mathbf{R R}(\mathbf{9 5} \% \mathbf{C l})$ \\
\hline \begin{tabular}{l} 
AORH counties* \\
\hline 1991 (reference)
\end{tabular} & 1.0 \\
\hline Annual increase 1992-5 & $1.01(0.99$ to 1.02$)$ \\
\hline Age $50-69$ years: & $1.82(1.70$ to 1.96$)$ \\
\hline $1996-7$ & $1.54(1.42$ to 1.66$)$ \\
\hline $1998-9$ & $1.56(1.42$ to 1.73$)$ \\
\hline 2000 & $0.89(0.70$ to 1.12$)$ \\
\hline 2000, age $70-74$ years & \\
\hline Non-A0RH counties & $0.87(0.84$ to 0.90$)$ \\
\hline All ages (1991-2000) & $1.00(0.99$ to 1.01$)$ \\
\hline Annual increase 1992-5 & \\
\hline Age 50-69 years: & $1.16(1.08$ to 1.25$)$ \\
\hline $1996-7$ & $1.31(1.22$ to 1.41$)$ \\
\hline $1998-9$ & $1.51(1.38$ to 1.67$)$ \\
\hline 2000 &
\end{tabular}

${ }^{*}$ Akershus, Oslo, Rogaland, Hordaland.

There was no significant increase in rates in the non-AORH counties in 1991-5 either. The increases in incidence for the age groups 50-69 years in the non-AORH counties were $16 \%$ (1996-7), 31\% (19989), and $51 \%$ (2000). The non-AORH counties had a $13 \%(10 \%$ to $16 \%)$ lower incidence than the AORH counties in the period 1991-2000.

Figure 2 shows the age specific rates for breast cancer in Sweden. During the period 1971-85 the annual increase in incidence rates was $0.8 \%(0.7 \%$ to $0.9 \%)$ for all age groups (table 2), and the incidence increased with age. ${ }^{1}$ In this period several large mammographic screening trials took place in Sweden. In the following decade the nationwide screening programme was

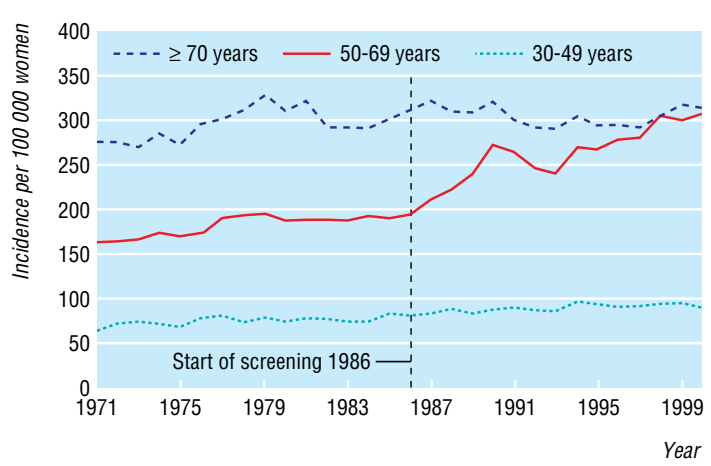

Fig 2 Age specific incidence of invasive breast cancer in Sweden and for age groups 30-49, 50-69, and >69 years. Vertical line indicates start of organised screening in Sweden (1986) 
Table 2 Estimated relative risks of breast cancer (excluding ductal carcinoma in situ) in Sweden

\begin{tabular}{lc} 
& $\mathbf{R R}(\mathbf{9 5} \% \mathbf{C l})$ \\
\hline 1971 (reference) & 1.0 \\
\hline Annual increase: & \\
\hline $1972-85$ & $1.008(1.007$ to 1.009$)$ \\
\hline $1986-2000$ & $1.001(0.998$ to 1.003$)$ \\
\hline Age $50-69$ years: & \\
\hline $1986-9$ & $1.06(1.03$ to 1.09$)$ \\
\hline $1990-3$ & $1.31(1.28$ to 1.34$)$ \\
\hline $1994-6$ & $1.28(1.25$ to 1.32$)$ \\
\hline $1997-2000$ & $1.45(1.41$ to 1.49$)$ \\
\hline Age $70-74$ years: & \\
\hline $1994-6$ & $0.98(0.93$ to 1.03$)$ \\
\hline $1997-2000$ & $1.01(0.96$ to 1.05$)$ \\
\hline Age $75-79$ years: & \\
\hline $1997-2000$ & $0.88(0.84$ to 0.92$)$ \\
\hline
\end{tabular}

implemented, and a substantial increase in incidence occurred in the screened age groups.

From 1986 to 2000 the incidence rate in the screened group increased by $45 \%$ (41\% to $49 \%$ ), whereas there were no significant increases or falls in other age groups. The consequence is that the incidence rates for the age group 50-69 years in recent years have become almost equal to incidence rates for the age group $\geq 70$ years (fig 2 ). There was no significant decline in the incidence rate for the age group 70-74 years, either in 1994-6 or in 1997-2000 (in 1997 about $96 \%$ of all women in this group had been invited at least once to screening before they had turned 70 years), but for the age group 75-79 years a small (12\%) reduction in incidence was present in the last period.

\section{Discussion}

We found that the introduction of mammographic screening programmes was associated with more than a $50 \%$ increase in the incidence of invasive breast cancer for the age group 50-69 years in Norway and a 45\% increase in Sweden. This increase related to screening is much higher than the $2 \%$ previously predicted ${ }^{1}$ and the $30 \%$ reported in the screening trials. ${ }^{4}$ If most of this increase were to be compensated for by a subsequent drop in the incidence after age 69 years, then this drop would have to be extreme. However, we found no significant reduction in incidence for the age group $70-74$ years in either country and only a small $(12 \%)$ reduction in the age group 75-79 years in Sweden. If the $12 \%$ incidence reduction becomes significant in the AORH counties, it will compensate for only $3 \%$ of the 54\% incidence increase in the age group 50-69 years.

The discrepancy between our observed increase of around $50 \%$ and the $30 \%$ increase reported in the screening trials may be explained by differences in mammographic techniques ${ }^{9}$ or by the mammographic screening in the control groups ${ }^{4}$ of the trials.

We cannot rule out the possibility of an underlying increase in incidence for women aged above 50 years in Sweden after 1986. However, a 0.8\% annual increase (as seen in Sweden before 1986) can explain only a small part of the $45 \%$ increase in Sweden in the age group 50-69 years. Furthermore, a 0.8\% increase will cover only a small part of the $50 \%$ decline in the age group 70-74 years that Boer et al predicted. ${ }^{1}$

\section{What is already known on this topic}

Nationwide mammography screening results in a substantial increase in the reported incidence of invasive breast cancer in the invited population

It was expected that most of this increase would be compensated for by falling incidence rates when the women are no longer invited for screening

\section{What this study adds}

In Norway and Sweden the increase in incidence related to screening in the invited population has not been followed by a similar fall incidence at later ages

The level of overdiagnosis in nationwide mammography screening is much higher than previously thought

As the increase in incidence in Norwegian counties was closely associated with the introduction of screening, ${ }^{9}$ it is unlikely that it was caused by other factors (such as hormone replacement therapy). We also think it unlikely that increased detection of low malignancy lesions due to screening after age 69 years may hide any substantial underlying decline in incidence after age 69 years.

Our analysis is fairly simple but can be reproduced by a more sophisticated statistical method similar to that used by Etzioni et al. ${ }^{10}$ They found that one in three prostate cancers diagnosed by screening for prostate specific antigen is an overdiagnosis, which is similar to what we estimate for mammographic screening.

Overdiagnosis (and overtreatment) due to mammographic screening has mostly been discussed in relation to the increasing rates of ductal carcinoma in situ, ${ }^{11}$ while little attention has been paid to the rates of invasive cancer. Our results suggest that increasing rates of invasive cancer are a more serious problem than ductal carcinoma in situ. We did not include ductal carcinoma in situ in our analyses, but if it had been included, then the relative risk would be 1.80 (1.71 to 1.90 ) in the AORH counties in 1998-9.

We conclude that after the introduction of screening programmes in Norway and Sweden one third of all cases of invasive breast cancer in the age group 50-69 are overdiagnosed-that is, without screening these cases would not have been detected during the patients' lifetime. The issue of overdiagnosis needs to be properly examined when the mammographic screening programmes in Nordic countries are evaluated in the next few years. Finally, we claim that women cannot make an informed choice on screening unless the level of overdiagnosis is properly explained to them. ${ }^{12}$

Contributors: P-HZ and JM conceived and implemented the study, conducted the analysis, and wrote the manuscript. BHS assisted in data analysis and writing. P-HZ is guarantor.

Funding: None.

Competing interests: None declared.

Ethical approval: Not required. 
1 Boer R, Mamerdam P, de Koning H, van Oortmarssen G. Extra incidence caused by mammographic screening. Lancet 1994;343:979.

2 Van den Akker-van Marle ME, Reep-van den Bergh CM, Boer R, Del Moral A, Ascunce N, de Koning HJ. Breast cancer screening in Navarra: interpretation of a high detection rate at the first screening round and low rate at the second screening round. Int J Cancer 1997;73:464-9. 3 Health Council of the Netherlands. The benefit of population screening for
breast cancer with mammography. Hague: Health Council of the Netherlands (Gezundheitsraad), 2002 (publication No 2002/03E).

4 Olsen O, Gøtzsche PC. Cochrane review on screening for breast cancer with mammography. Lancet 2001;358:1340-2.

5 Hakama M, Pukkala E, Söderman B, Day N. Implementation of screening as a public health policy: issue in design and evaluation. J Med Screen $1999 \cdot 6 \cdot 209-16$

6 Harmer C, Staples M, Kavanagh AM. Evaluation of breast cancer incidence: is the increase due entirely to mammographic screening? $\mathrm{Can}$ cer Causes Control 1999;10:333-7.
7 Cancer incidence in Sweden 2000. Stockholm: National Board of Health and Welfare (Socialstyrelesen), 2002

8 Cancer in Norway 2000. Oslo: Cancer Registry of Norway (Kreftregisteret),

9 Mammografiprogrammet $i$ Norge. Evaluering av proveprosjektet 1996-2000. Oslo: Cancer Registry of Norway (Kreftregisteret), 2000.

10 Etzioni R, Penson DF, Legler JM, di Tommaso D, Boer R, Gann PH, et al. Overdiagnosis due to prostate-specific antigen screening: lessons from US prostate cancer incidence trends. J Natl Cancer Inst 2002;94: 981-90.

11 Fletcher SW, Elmore JG. Mammographic screening for breast cancer. $N$ Engl J Med 2003;348:1672-80.

12 Thornton H, Edwards A, Baum M. Women need better information about routine mammography. BMJ 2003;327:101-3.

(Accepted 22 January 2004)

doi $10.1136 /$ bmj.38044.666157.63

\section{Hospitals' star ratings and clinical outcomes: ecological study}

Kathy Rowan, David Harrison, Anthony Brady, Nick Black

Intensive Care

National Audit and

Research Centre

London

WC1H 9HR

Kathy Rowan

director

David Harrison

statistician

Anthony Brady

senior statistician

London School of

Hygiene and

Tropical Medicine,

London

WC1E 7HT

Nick Black

professor of health

services research

Correspondence to:

N Black

nickblack@

lshtm.ac.uk

BMJ 2004;328:924-5
The English Department of Health is developing global measures of the performance of all NHS bodies, including 166 acute hospital trusts. Since 2000-1, the trusts get zero, one, two, or three stars to indicate performance. ${ }^{1}$ This rating may not reflect the effectiveness of clinical care measured in patient outcomes because of the lack of accurate routine data. ${ }^{2}$ One exception is in adult critical care ${ }^{3}$; we checked whether a hospital's rating provided an indication of its clinical outcomes.

\section{Methods and results}

We compared the 2001-2 rating of 102 acute hospital trusts for which we had validated data for that year. We calculated each patient's predicted risk of death before discharge from hospital ${ }^{4}$ and compared it with actual mortality for all admissions in 2001-2 for each unit.

We compared rating with crude mortality at the patient level rather than aggregated by hospital; our sample of hospitals with all hospitals; and university with non-university hospitals using $\chi^{2}$ tests for trend. We compared rating with size of intensive care unit and mean age of patients, using Spearman's $\rho$. We calculated confidence intervals for mortality adjusted for risk, using logistic regression of mortality on rating and predicted log odds of mortality. We tested rating and adjusted mortality using the likelihood ratio test.

The distribution of ratings for the 102 acute hospital trusts was similar to that for all 166 trusts $\left(\chi^{2}=1.7\right.$; $\mathrm{P}=0.19$ ). Rating was associated with teaching status (university hospitals had more stars than nonuniversity hospitals $-52 \% v 29 \%$ had three, $38 \% v 45 \%$ had two, $5 \%$ v $19 \%$ had one, $5 \%$ v $7 \%$ had zero; $\chi^{2}=3.9$; $\mathrm{P}=0.05$ ) but not size of its critical care unit (Spearman's $\rho=0.09 ; \mathrm{P}=0.34$ ).

Rating and crude mortality for critical care admissions were significantly associated $\left(\chi^{2}=4.1 ; \mathrm{df}=1\right.$; $\mathrm{P}=0.04$ ) (figure): mortality in trusts with three stars was about $4 \%$ lower than in trusts with zero stars. However, case mix of critical care admissions also differed considerably. Rating was inversely associated with the mean age of critical care admissions $(\rho=-0.19$;

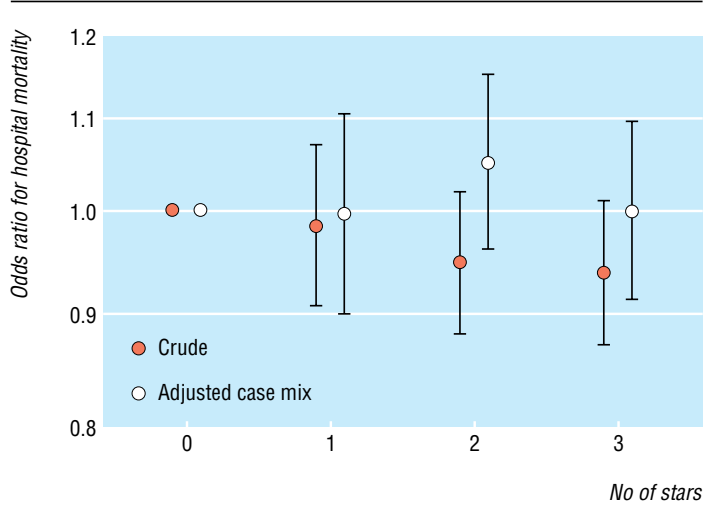

Odds ratio for crude case mix and for case mix adjusted for risk hospital mortality by star rating of acute hospital trust

$\mathrm{P}=0.04)$. The association between rating and hospital mortality was no longer significant when case mix differences were taken into account $(\mathrm{P}=0.4)$ (figure).

\section{Comment}

For adult critical care, star ratings do not reflect the quality of clinical care provided by hospitals. Patients do just as well in a trust with no stars as they do in one with three stars. Crude mortality data are misleading because they ignore the fact that higher rated trusts tend to be teaching institutions with patients who are less severely ill on admission to critical care units.

We did not expect to find an association between the rating of the whole trust and the effectiveness of critical care. Firstly, hospitals are complex organisations containing many services; performance across a hospital will not be uniform-a poorly rated hospital may contain some excellent services and vice versa. Secondly, ratings are determined by a small number of process measures; outcome measures play only a small

This article was posted on bmj.com on 23 January 2004 http://bmj.com/cgi/doi/10.1136/bmj.38007.694745.F7 